\title{
Spinal cord stimulation for chronic non-cancer pain: a review of current evidence and practice
}

\author{
Stanley SC Wong, CW Chan, CW Cheung *
}

\begin{abstract}
A B S T R A C T
Spinal cord stimulation provides analgesia through electrical stimulation of the dorsal column of the spinal cord via electrode leads placed into the epidural space. In traditional tonic stimulation, a painful sensation is replaced with paraesthesia. Spinal cord stimulation is effective in reducing neuropathic pain, enhancing function, and improving quality of life in different chronic pain conditions. Currently, there is most evidence to support its use for failed back surgery syndrome when multidisciplinary conventional management is unsuccessful. Temporary trial leads are inserted in carefully selected patients to test their responsiveness prior to permanent implantation. Newer neuromodulation modalities are now available. These include burst stimulation, high-frequency stimulation, and dorsal root ganglion stimulation. Results are encouraging
\end{abstract}

to date, and they may provide superior analgesia and cover for deficiencies of traditional tonic stimulation. Although complications are not uncommon, they are rarely life threatening or permanently disabling. Nonetheless, device removal is occasionally needed.
Hong Kong Med J 2017;23:517-23
DOI: $10.12809 / \mathrm{hkmj} 176288$
${ }^{1}$ SSC Wong, MB, BS, FHKAM (Anaesthesiology)
${ }^{2}$ CW Chan, MB, BS, FHKAM (Anaesthesiology)
${ }^{1}$ CW Cheung *, MD, FHKAM (Anaesthesiology)
${ }^{1}$ Laboratory and Clinical Research Institute for Pain, Department of Anaesthesiology, The University of Hong Kong, Pokfulam, Hong Kong
2 Department of Anaesthesiology, Queen Mary Hospital, Pokfulam, Hong Kong
* Corresponding author: cheucw@hku.hk

\section{Introduction}

Neuromodulation involves the use of an advanced medical device to alter the activity of the nervous system. Spinal cord stimulation (SCS) is a neuromodulation technique that reduces pain by electrical stimulation of the dorsal column of the spinal cord. Electrical leads are placed into the epidural space either percutaneously or by laminotomy. The electrical leads are then connected to a power source, either an implantable pulse generator (IPG) or a radiofrequency unit. The IPG can be surgically implanted under the skin. ${ }^{1}$

A recent study showed that $28.7 \%$ of people in Hong Kong have chronic pain. ${ }^{2}$ This can be a major reason for reduced psychosocial function, impaired quality of life, and increased health care costs. ${ }^{2}$ Spinal cord stimulation mainly targets neuropathic pain and has limited efficacy for nociceptive pain. ${ }^{1}$ Neuropathic pain is common in Hong Kong, affecting $9.03 \%$ of the total population and $14.7 \%$ of chronic pain sufferers. ${ }^{2}$ For some patients, severe pain persists despite multidisciplinary management. Strong opioids are often prescribed, despite their side-effects and lack of good longterm efficacy. ${ }^{3}$ For some of these patients, SCS offers effective pain relief and consequent improved function. The Neuromodulation Appropriateness Consensus Committee (NACC) recommends use of neuromodulation techniques before long- term opioids for neuropathic pain. ${ }^{4}$ Spinal cord stimulation is currently approved by the Food and Drug Administration (FDA) for chronic pain of the trunk and limbs, low back pain, leg pain, and failed back surgery syndrome (FBSS). European guidelines also approve the use of SCS for refractory angina pectoris and peripheral limb ischaemia.

More recently, newer neurostimulation modalities have been introduced. These include high-frequency spinal cord stimulation (HF-SCS), burst stimulation, and dorsal root ganglion (DRG) stimulation. These techniques may improve efficacy and compensate for deficiencies of traditional tonic SCS.

\section{Patient selection}

Careful patient assessment is required to confirm the indication, assess suitability, and exclude contraindications. The NACC recommends that SCS be considered after conventional multidisciplinary management (usually 3-6 months) has failed in patients with neuropathic or mixed pain.,5 Patients should have a well-defined, non-cancer, physiological cause of pain. ${ }^{4}$ Contra-indications should be excluded. These include systemic or local infection, coagulopathy, need for anticoagulant or antiplatelet therapy that cannot be temporarily stopped, and uncontrolled psychiatric/psychological problems. ${ }^{5}$ Depression, anxiety, somatisation, and poor coping 


\section{脊髓刺激療法治理非癌症的慢性疼痛：回顧當前 證據和臨床實踐}

黃守正、陳智榮、張志偉

脊髓刺激療法透過放置於椎管硬膜外腔後部的電極引線, 通過電流刺 激脊髓以達至鎮痛效果。在傳統的持續性脊髓刺激中, 刺痛感取代了 疼痛的感覺。脊髓刺激療法能有效減少神經性疼痛、恢復因疼痛失去 的生活功能，為不同程度的慢性疼痛病人改善生活質素。目前有很多 證據顯示, 當傳統跨專科療法失效時, 脊髓刺激療法可改善脊椎手術 後疼痛症候群。醫生在謹慎篩選病人後會先做測試, 把電極導線放入 病人體內, 測試效果滿意後才永久植入神經刺激器。現在經已有更新 的神經調節模式, 包括爆發刺激、高頻刺激和背根神經節刺激, 治療 效果令人鼓舞。迄今為止, 這些新模式可能為傳統的持續性脊髓刺激 的不足提供更佳的鎮痛效果。雖然併發症偶爾會發生, 但很少會危及 生命或造成永久性傷殘。然而, 也有可能需要摘除電極引線設備。 are associated with poorer outcomes following SCS implantation so psychological evaluation is advised to ensure that there are no uncontrolled psychiatric/ psychological issues..$^{5-7}$ Unresolved social issues, in particular those related to litigation and secondary gain, should also be excluded. The patient should have a reasonable cognitive ability, reasonable expectations, and be motivated to comply with the post-implantation rehabilitation programme.

\section{Spinal cord stimulation: technical aspects}

The SCS device comprises electrode leads, an extension cable, a pulse generator, and a programmer. Most percutaneous leads have four to 20 electrode contacts, and these are introduced into the epidural
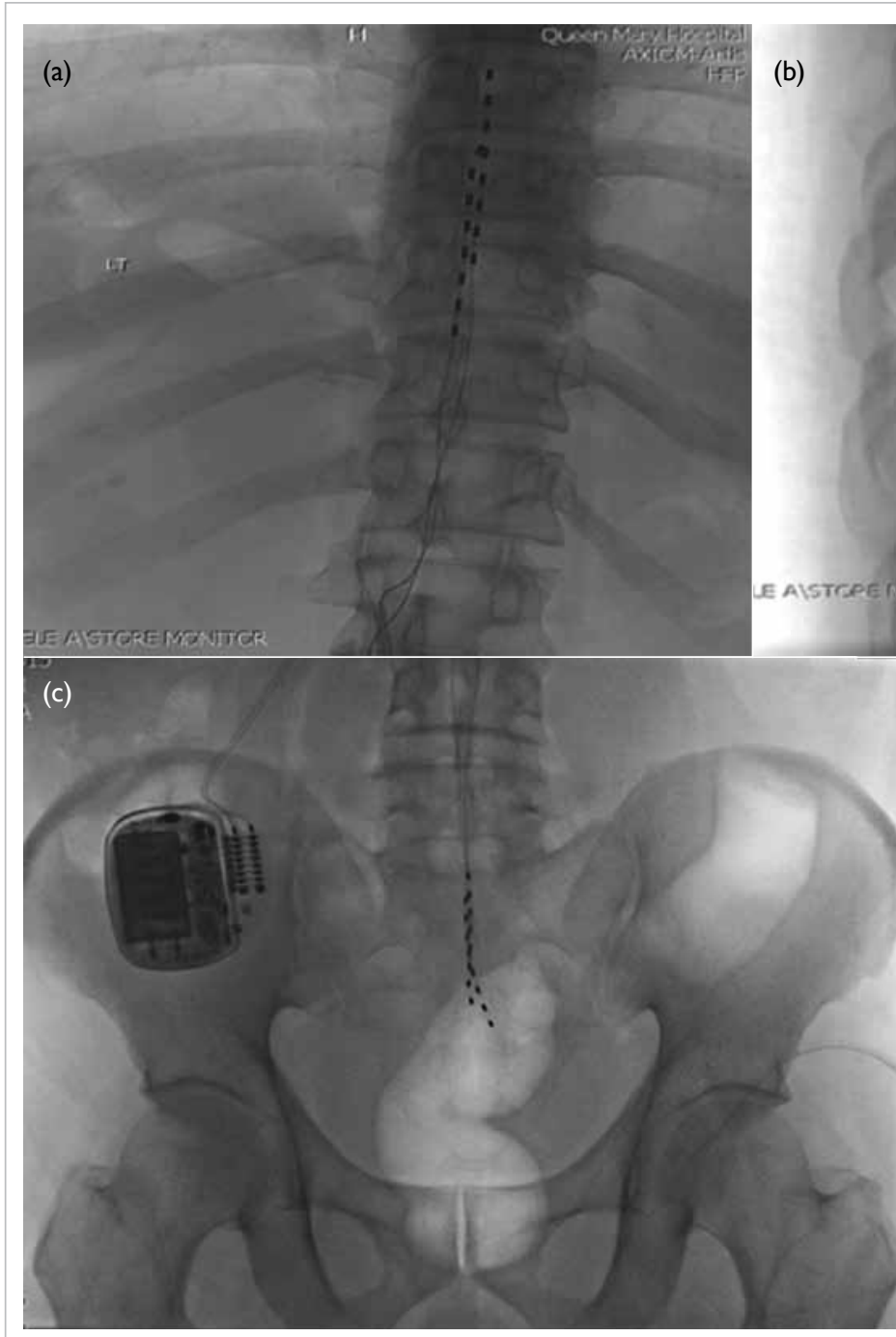

(b)

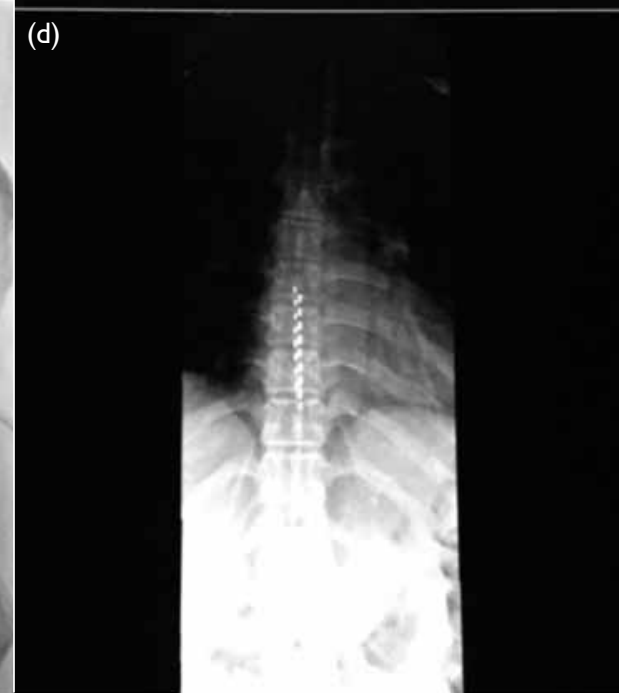

FIG. Implantation techniques of spinal cord stimulation (courtesy of the Division of Pain Medicine, Department of Anaesthesiology, Queen Mary Hospital)

(a) Anterior-posterior fluoroscopic image of percutaneous leads placed in the thoracic epidural space. (b) Lateral fluoroscopic image of percutaneous leads placed in the thoracic epidural space. (c) The implantable pulse generator and retrograde percutaneous leads for management of coccydynia. (d) Anterior-posterior fluoroscopic image of percutaneous paddle lead placed in the thoracic epidural space 
space via an epidural needle. In the percutaneous approach, entry of the epidural needle into the epidural space is achieved using the loss of resistance (LOR) technique with a LOR syringe under X-ray guidance. After entry of the needle into the epidural space, the electrode leads are advanced to the target level under live X-ray screening to stimulate the dorsal column (Fig). The electrodes are then placed around the midline of the epidural space to avoid stimulating the dorsal nerve roots that can result in uncomfortable motor responses and dysaesthesia. ${ }^{1}$ Usually two electrode leads are placed. The target level depends on the area that needs to be stimulated $\left(T_{a b l e}{ }^{1}\right)$. The final position of the electrode lead is adjusted based on patient feedback during the procedure to ensure that the area of stimulation matches the area of pain. This is called paraesthesia mapping.

Three parameters are adjusted to provide neurostimulation: frequency, amplitude, and pulse width. The frequency determines the quality of paraesthesia: $50 \mathrm{~Hz}$ is most commonly used. ${ }^{1}$ The pulse width affects the size of the area of paraesthesia and amplitude affects stimulation intensity. ${ }^{1} \mathrm{~A}$ trial period where temporary electrode leads are inserted for approximately 5 to 7 days is needed to determine analgesic efficacy. ${ }^{1}$ Pain relief of $50 \%$ or greater is considered a positive trial. ${ }^{5}$ This should be accompanied by a stable level of daily activity and use of analgesic drugs. After a successful trial, a permanent SCS implant can be placed several weeks to 1 month later. In permanent SCS implantation, the electrode leads are tunnelled and connected to the IPG that is implanted under the skin in the gluteal region or lower abdominal area.

\section{Specific pain conditions}

\section{Failed back surgery syndrome}

Failed back surgery syndrome is present when persistent pain (axial back pain and/or radicular leg pain) continues despite back surgery. It is the most common indication for SCS with level I-II

TABLE. A guide for level of initial lead placement for different anatomical areas'

\begin{tabular}{lc}
\hline Target area in the body & $\begin{array}{c}\text { Level of electrode lead } \\
\text { placement }\end{array}$ \\
\hline Posterior occipital region & $\mathrm{C} 2$ \\
\hline Upper extremity & $\mathrm{C} 2-\mathrm{C} 5$ \\
\hline Hand & $\mathrm{C} 5-\mathrm{C} 6$ \\
\hline Chest wall and angina & $\mathrm{T} 1-\mathrm{T} 4$ \\
\hline Thigh and knee & $\mathrm{T} 9-\mathrm{T} 10$ \\
\hline Lower leg and ankle & $\mathrm{T} 10-\mathrm{T} 12$ \\
\hline Foot & $\mathrm{T} 11-\mathrm{L} 1$ \\
\hline
\end{tabular}

evidence supporting the use of traditional tonic SCS for managing FBSS. ${ }^{8}$ In the PROCESS (Prospective Randomised Controlled Multicentre trial of the Effectiveness of Spinal Cord Stimulation) trial, a multicentre randomised controlled trial, SCS together with conservative medical management was superior to conservative medical management alone in reducing leg pain, improving quality of life, and enhancing functional capacity in patients with FBSS. ${ }^{9}$ At 12 months, $48 \%$ of patients with SCS plus medical management obtained $50 \%$ or greater leg pain reduction versus $18 \%$ in those with medical management only. ${ }^{9}$

A systematic review of cost-effectiveness showed that SCS has a higher initial cost, but is more cost-effective in the long term compared with conventional medical management. ${ }^{10}$ Such stimulation technique is also more cost-effective than reoperation. ${ }^{11}$

\section{Complex regional pain syndrome}

Complex regional pain syndrome (CRPS) can cause disabling pain and dysfunction of the limbs. In a randomised controlled trial to compare SCS plus physical therapy with physical therapy alone in the treatment of CRPS, patients with SCS had better pain control and health-related quality of life. ${ }^{12}$ In those with an implanted SCS, 39\% experienced 'much improved' global perceived effect versus only $6 \%$ of control patients. ${ }^{12}$ At 2 years of follow-up, the visual analogue pain scale decreased by $2.1 \mathrm{~cm}$ in the SCS-plus-physical therapy group, but did not change in the physical therapy-only group. ${ }^{13}$ By 3 years after implantation, there was no longer any significant difference between the groups but 95\% of patients with an implant would choose to repeat the treatment. ${ }^{14}$ A cost-effective analysis for CRPS over a 15-year period indicated that SCS was costeffective. $^{15}$

\section{Refractory angina pectoris and peripheral ischaemic limb pain}

Spinal cord stimulation can cause vasodilation with consequent improved blood flow. This is an option in the management of patients with severe coronary artery disease and angina and for whom revascularisation is unsuitable. It is associated with reduced angina attacks, reduced nitrate use, and increased exercise duration compared with conventional medical management. ${ }^{16}$ When compared with coronary artery bypass grafting, patients with SCS achieved similar symptom relief, but required more nitrate and had lower exercise capacity. ${ }^{17}$ It has been shown that SCS is costeffective for refractory angina. ${ }^{18}$

Spinal cord stimulation is also a therapeutic option for patients with critical limb ischaemia where surgical treatment is not possible. A meta- 
analysis of randomised controlled trials showed improved analgesia and limb salvage rates. ${ }^{19}$

\section{Other conditions}

Other chronic pain conditions where SCS may be useful include painful diabetic peripheral neuropathy, post-herpetic neuralgia, abdominal/ pelvic pain, post-amputation pain, and chest wall pain syndromes. Results from a small randomised controlled trial indicate better pain relief with SCS compared with medical treatment for painful diabetic neuropathy. ${ }^{20}$ Evidence for the other conditions is limited.

\section{Newer neuromodulation modalities}

Newer neuromodulation modalities have been introduced in recent years, and they may further improve patient outcomes. These include HF-SCS, burst stimulation, and DRG stimulation. The HF-SCS and burst stimulation differ in their programming to traditional tonic SCS. Traditional tonic SCS delivers a consistent set of pulses at a certain amplitude, frequency, and pulse width. For tonic SCS, pulse width is usually $300-500 \mu \mathrm{s}$, amplitude is $2-5 \mathrm{~mA}$, and frequency is $30-100 \mathrm{~Hz} \cdot{ }^{5,21}$ Axial back pain, and groin and foot pain are areas that are more difficult to target with tonic SCS. ${ }^{22}$ Tonic SCS produces paraesthesia to surround and replace the area of pain. Some patients, however, find this tingling sensation unpleasant. This can be especially problematic with change in body position (especially from sitting to standing). ${ }^{4}$ Newer neuromodulation modalities may help tackle some of these problems.

\section{Burst stimulation}

Burst stimulation provides high-density stimulation where groups of high-frequency impulses or 'bursts' are delivered intermittently at $40 \mathrm{~Hz}$. Within each 'burst', five pulses with a 1-ms pulse width and 1-ms spike interval are delivered at a high frequency of 500 $\mathrm{Hz} .{ }^{21}$ Amplitude is reduced with the aim of providing paraesthesia-free stimulation.

Current evidence regarding burst SCS is limited. A small randomised controlled trial showed that burst stimulation reduced back and general pain more than that of tonic SCS. ${ }^{23}$ A systematic review, however, concluded that there was insufficient evidence to support or discourage use of burst SCS for chronic back and limb pain..$^{21}$ Full results of the SUNBURST (Success Using Neuromodulation with BURST) study, a multicentre randomised controlled trial comparing burst SCS with traditional tonic SCS in 121 patients, are awaited. The preliminary results involving 85 patients followed up at 24 weeks show statistically better analgesia with burst stimulation (mean difference of $6 \mathrm{~mm}$ visual analogue scale points), although the clinical significance appears to be small. ${ }^{24}$ Burst SCS was preferred to tonic by $69 \%$ of patients. ${ }^{24}$ Burst SCS may provide improved pain control (particularly the back) without paraesthesia.

\section{High-frequency stimulation}

The HF-SCS provides electrical stimulation at a high frequency of $1 \mathrm{kHz}$ to $10 \mathrm{kHz} ; 10 \mathrm{kHz}$ is most frequently used.$^{25}$ Such therapy ensures paraesthesiafree stimulation but is not available in Hong Kong. Unlike other forms of SCS, lead implantation for HF-SCS is based only on anatomical landmarks so paraesthesia mapping that requires a patient to be woken up from sedation for assessment is avoided. Implantation without paraesthesia mapping makes the procedure simpler, and duration of surgery is more predictable.

Clinical studies support HF-SCS for back and leg pain. ${ }^{26,27}$ This therapy has been shown to reduce back and leg pain, decrease opioid use, and improve sleep and functional status. ${ }^{26}$ A large randomised controlled trial, SENZA, compared high-frequency $10-\mathrm{kHz}$ stimulation with traditional tonic SCS for back and leg pain in 198 patients. ${ }^{27}$ Patients with HF-SCS reported significantly better back and leg pain relief than those who received tonic $\mathrm{SCS} .{ }^{27}$ At 24-month follow-up, $76.5 \%$ and $72.9 \%$ of patients with HF-SCS had at least a 50\% reduction in back pain and leg pain, respectively. ${ }^{28}$ This reduction of pain was significantly higher than that for patients using tonic stimulation, where only $49.3 \%$ had at least a $50 \%$ reduction in back pain and leg pain. ${ }^{28}$ Of note, HF-SCS also resulted in better outcomes in terms of disability and patient satisfaction, and one third of the patients had reduced opioid consumption. ${ }^{27} \mathrm{~A}$ retrospective study showed that $68 \%$ of patients who did not receive satisfactory pain relief with tonic SCS had a positive HF-SCS trial, suggesting that HF-SCS may salvage patients who are not responsive to tonic SCS. $^{29}$ The FDA has labelled HF-SCS at $10 \mathrm{kHz}$ as superior to traditional tonic SCS. ${ }^{22}$

\section{Dorsal root ganglion stimulation}

Stimulation of DRG involves insertion of the electrode lead into the epidural space and then positioning of it into the neural foramen laterally to stimulate the DRG. ${ }^{1}$ While tonic, burst, and HF-SCS act on second-order neurons in the spinal cord, DRG exerts its effect on the primary afferent level. The DRG is especially useful for targeting discrete focal areas of pain, such as the groin and foot that are difficult to target using other SCS modalities. Another advantage of DRG stimulation is a lack of change in paraesthesia intensity with change in position, possibly due to the stable position of the DRG. ${ }^{30}$

Clinical studies have shown encouraging results for DRG stimulation. A non-comparative 
study of patients with FBSS, CRPS, and chronic post-surgical pain reported overall pain reduction, improved mood, and better quality of life with DRG stimulation. ${ }^{31}$ The ACCURATE trial was the largest randomised controlled trial to compare DRG stimulation against traditional tonic SCS. ${ }^{32}$ In 152 patients who had CRPS and/or peripheral causalgia of the lower limbs for over 6 months, DRG stimulation resulted in better pain control at 3 and 12 months, greater improvement in quality of life, better functional status, and better psychological well-being. ${ }^{32}$ With DRG stimulation, $74.2 \%$ of patients had over $50 \%$ pain reduction at 12 months, compared with only $53 \%$ of those with traditional tonic stimulation. ${ }^{32}$ The FDA has approved the use of DRG stimulation for the treatment of lower-limb CRPS.

\section{Complications}

The overall safety profile of SCS is good and most complications can be reversed by removal of the implant. Incidences of complications range from $30 \%$ to $40 \%$, but life-threatening complications are rare. ${ }^{33,34}$

\section{Hardware problems}

Notable hardware problems include electrode lead migration, lead fracture and malfunction, and battery failure. Lead migration is the most common complication occurring in $2.1 \%$ to $27 \%$ of cases, with a mean of $15.49 \% .^{33}$ One study showed that it was the most common reason for surgical revision apart from battery change. ${ }^{35}$ Lead migration usually presents as a change in area of paraesthesia and loss of analgesia. Diagnosis can be confirmed with $\mathrm{X}$-ray that should show an unintended relocation of the lead. Minor lead migrations can be managed by reprogramming the stimulator. If this is unsuccessful, surgical repositioning is required.

The incidence of electrode lead fracture ranges from $0 \%$ to $10.2 \%$, with a mean of $6.37 \%{ }^{33}$ Lead fracture presents as loss of pain relief. X-ray may sometimes show the site of fracture. An impedance check needs to be performed to diagnose lead fracture, and this usually exceeds $4000 \mathrm{ohms}^{34}$ The fractured lead has to be removed and a new one placed.

Other less common hardware complications include battery failure and extension wire failures. Battery failure occurs when the battery inside the IPG becomes exhausted and requires replacement before the expected date; its incidence is around $1.9 \% .^{36}$ Rarely, extension cable breakage or disconnection can occur, and most will require replacement. ${ }^{34}$

\section{Biological complications}

Biological complications include infection, pain, or
BOX. Strategies to reduce the risk of infection after spinal cord stimulation implantation ${ }^{34}$

Careful patient selection

Pre-surgical bath with antiseptic agent

Antiseptic preparation of surgical sites

Minimising hospital stay

Antibiotic prophylaxis

Surgical implantation under aseptic conditions

Minimising tissue trauma

Avoiding placement of devices directly under incision lines

Applying occlusive antiseptic wound dressings

Postoperative antibiotics (controversial)

discomfort over device components, dural puncture, skin erosion, and neurological injury.

Infection is a major complication of SCS implantation, and a common reason for removal of the device. Infection rate ranges from $2.5 \%$ to $14 \%$, with a mean incidence of around $5 \% .^{34}$ Severe infection such as epidural abscess is rare. Infection involving the subcutaneous IPG pocket is more common than infection involving the spinal canal. In a review of over 100 cases of infection, $48 \%$ were caused by staphylococcus and $3 \%$ by pseudomonas. ${ }^{37}$ Some risk factors included diabetes, debility, malnutrition, obesity, a very thin body, autoimmune disorders, use of steroids, pre-existing infection, poor hygiene, urinary or faecal incontinence, malabsorption syndrome, and decubitus ulcers. ${ }^{37}$

Clinical symptoms and signs of infection include fever, local pain, erythema, swelling, wound secretion, and dehiscence. Maintaining a high index of clinical suspicion is important for early diagnosis, and antibiotic treatment should be started without waiting for culture results. ${ }^{37,38}$ A positive staining and/or culture of micro-organisms from the surgical wound or implant site confirms the diagnosis. Superficial infections may be successfully managed with antibiotics alone. Deep infections close to the device usually necessitate device removal. Overall, treatment of infection without device removal is associated with lower success rates, and it is the reason most infections ultimately result in device removal. ${ }^{37}$ After infection is controlled, the same device can be replaced in an anatomical location removed from the site of the infection. ${ }^{34,37}$ Some strategies to reduce risk of infection are listed in the Box. $^{34}$

Neurological injury is very rare but can occur as a result of direct spinal cord injury from needle puncture or lead placement. Epidural haematoma may rarely develop and lead to delayed neurological damage. The incidence of epidural haematoma and paralysis has been reported to be $0.3 \%$ and $0.03 \%$, respectively. ${ }^{36}$ Early surgical consultation for exploration and decompression is required if epidural haematoma is diagnosed. 
Patients sometimes experience pain around the SCS device such as the IPG site. The mean incidence is around $6.15 \% .^{33}$ Pain is usually temporary and diminishes after 7 to 14 days. Inadvertent dural puncture can occur uncommonly during Tuohy needle insertion or electrode lead manipulation. The rate of dural puncture has been estimated to be $0 \%$ to $0.3 \%$, and this can result in post-dural puncture headache. ${ }^{36}$ Subcutaneous haematoma or seroma may develop, and they most commonly occur in the IPG pocket. The IPG pocket may subsequently become infected. Aspiration or surgical evacuation is occasionally indicated. Skin erosions by leads or hardware are rare, with an incidence of only $0.2 \% .^{36}$

\section{Implanter training and mentorship}

Appropriate training in SCS implantation is essential to ensure optimal outcomes. The NACC recommends fellowship training for at least 6 months, with at least 12 hours of continuing medical education directly related to neuromodulation each year. $^{5}$ Those without formal fellowship training should perform implantation only after appropriate hands-on training with active mentorship. ${ }^{5}$ During formal training, the trainee should perform 10 cases under supervision as the primary implanter. ${ }^{5}$

\section{Practice and challenges in Hong Kong}

Spinal cord stimulation is considered for management of significant chronic pain that is refractory to conventional management. It can be performed by pain physicians, orthopaedic surgeons, or neurosurgeons. A percutaneous approach by pain physicians and an open approach via laminotomy by surgeons have been performed. Patients typically undergo multidisciplinary assessment by the SCS surgeon, pain nurses, clinical psychologist, and physiotherapists. Suitable patients will undergo a trial of SCS and proceed to implant if successful.

Although SCS has been available for many years in other developed countries such as the United States, it has only started to attract more interest in Hong Kong over the last few years. Few SCS implants have been performed and therefore there are little local data about its use. Despite the presence of local expertise in SCS implantation, there is a lack of awareness and familiarity on the part of both medical professionals and the general public. This means that potentially suitable patients are rarely referred for an SCS trial. The cost of an SCS implant is around $\mathrm{HK} \$ 150000$, making it unaffordable for many patients. While SCS may be covered by medical insurance in some other developed countries, this is not the case in Hong Kong. There is also a lack of government funding. Education of the general public and medical professionals about chronic pain management and SCS, as well as financial support from the government is imperative in order to successfully implement SCS as an effective treatment option in Hong Kong. Competent SCS implanters who can produce good results are crucial to generate support from the government, other medical professionals, and the general public.

\section{Conclusion}

Spinal cord stimulation provides an effective treatment of various chronic pain conditions such as FBSS and CRPS. It reduces pain, improves function, increases patient satisfaction, improves quality of life, and is also cost-effective in the long term. The option of SCS should be considered after conservative management has failed. Careful patient selection and assessment including placement of trial leads are required before permanent SCS implantation. Newer neuromodulation modalities such as burst stimulation, HF-SCS, and DRG stimulation are producing promising results. Lifethreatening or debilitating complications are rare. Most complications can be reversed with device removal.

\section{Declaration}

All authors have disclosed no conflicts of interest.

\section{References}

1. Song JJ, Popescu A, Bell RL. Present and potential use of spinal cord stimulation to control chronic pain. Pain Physician 2014;17:235-46.

2. Cheung CW, Choi SW, Wong SS, Lee Y, Irwin MG. Changes in prevalence, outcomes, and help-seeking behavior of chronic pain in an aging population over the last decade. Pain Pract 2017;17:643-54.

3. Cheung CW, Chan TC, Chen PP, et al. Opioid therapy for chronic non-cancer pain: guidelines for Hong Kong. Hong Kong Med J 2016;22:496-505.

4. Deer TR, Mekhail N, Provenzano D, et al. The appropriate use of neurostimulation: avoidance and treatment of complications of neurostimulation therapies for the treatment of chronic pain. Neuromodulation Appropriateness Consensus Committee. Neuromodulation 2014;17:571-97; discussion 597-8.

5. Deer TR, Mekhail N, Provenzano D, et al. The appropriate use of neurostimulation of the spinal cord and peripheral nervous system for the treatment of chronic pain and ischemic diseases: the Neuromodulation Appropriateness Consensus Committee. Neuromodulation 2014;17:515-50; discussion 550.

6. Celestin J, Edwards RR, Jamison RN. Pretreatment psychosocial variables as predictors of outcomes following lumbar surgery and spinal cord stimulation: a systematic review and literature synthesis. Pain Med 2009;10:63953.

7. Nagel SJ, Lempka SF, Machado AG. Percutaneous spinal cord stimulation for chronic pain: indications and patient selection. Neurosurg Clin N Am 2014;25:723-33.

8. Grider JS, Manchikanti L, Carayannopoulos A, et al. 
Effectiveness of spinal cord stimulation in chronic spinal pain: a systematic review. Pain Physician 2016;19:E33-54.

9. Kumar K, Taylor RS, Jacques L, et al. Spinal cord stimulation versus conventional medical management for neuropathic pain: a multicentre randomised controlled trial in patients with failed back surgery syndrome. Pain 2007;132:179-88.

10. Bala MM, Riemsma RP, Nixon J, Kleijnen J. Systematic review of the cost-effectiveness of spinal cord stimulation for people with failed back surgery syndrome. Clin J Pain 2008;24:741-56.

11. North RB, Kidd D, Shipley J, Taylor RS. Spinal cord stimulation versus reoperation for failed back surgery syndrome: a cost effectiveness and cost utility analysis based on a randomized, controlled trial. Neurosurgery 2007;61:361-8; discussion 368-9.

12. Kemler MA, Barendse GA, van Kleef M, et al. Spinal cord stimulation in patients with chronic reflex sympathetic dystrophy. N Engl J Med 2000;343:618-24.

13. Kemler MA, De Vet HC, Barendse GA, Van Den Wildenberg FA, Van Kleef M. The effect of spinal cord stimulation in patients with chronic reflex sympathetic dystrophy: two years' follow-up of the randomized controlled trial. Ann Neurol 2004;55:13-8.

14. Kemler MA, de Vet HC, Barendse GA, van den Wildenberg FA, van Kleef M. Effect of spinal cord stimulation for chronic complex regional pain syndrome Type I: five-year final follow-up of patients in a randomized controlled trial. J Neurosurg 2008;108:292-8.

15. Kemler MA, Raphael JH, Bentley A, Taylor RS. The costeffectiveness of spinal cord stimulation for complex regional pain syndrome. Value Health 2010;13:735-42.

16. Hautvast RW, DeJongste MJ, Staal MJ, van Gilst WH, Lie KI. Spinal cord stimulation in chronic intractable angina pectoris: a randomized, controlled efficacy study. Am Heart J 1998;136:1114-20.

17. Mannheimer C, Eliasson T, Augustinsson LE, et al. Electrical stimulation versus coronary artery bypass surgery in severe angina pectoris: the ESBY study. Circulation 1998;97:1157-63.

18. Kumar K, Rizvi S. Cost-effectiveness of spinal cord stimulation therapy in management of chronic pain. Pain Med 2013;14:1631-49.

19. Ubbink DT, Vermeulen H. Spinal cord stimulation for nonreconstructable chronic critical leg ischaemia. Cochrane Database Syst Rev 2013;(2):CD004001.

20. Slangen R, Schaper NC, Faber CG, et al. Spinal cord stimulation and pain relief in painful diabetic peripheral neuropathy: a prospective two-center randomized controlled trial. Diabetes Care 2014;37:3016-24.

21. Hou S, Kemp K, Grabois M. A systematic evaluation of burst spinal cord stimulation for chronic back and limb pain. Neuromodulation 2016;19:398-405.

22. Verrills P, Sinclair C, Barnard A. A review of spinal cord stimulation systems for chronic pain. J Pain Res 2016;9:48192.

23. De Ridder D, Plazier M, Kamerling N, Menovsky T, Vanneste $S$. Burst spinal cord stimulation for limb and back pain. World Neurosurg 2013;80:642-9.e1.

24. Deer TR. SUNBURST Trial Results. Proceedings of the 19th North American Neuromodulation Society Annual Meeting; 2015 Dec 10-13; Las Vegas, USA.

25. Russo M, Van Buyten JP. 10-kHz high-frequency SCS therapy: a clinical summary. Pain Med 2015;16:934-42.

26. AI-Kaisy A, Van Buyten JP, Smet I, Palmisani S, Pang D, Smith T. Sustained effectiveness of $10 \mathrm{kHz}$ high-frequency spinal cord stimulation for patients with chronic, low back pain: 24-month results of a prospective multicenter study. Pain Med 2014;15:347-54.

27. Kapural L, Yu C, Doust MW, et al. Novel 10-kHz highfrequency therapy (HF10 therapy) is superior to traditional low-frequency spinal cord stimulation for the treatment of chronic back and leg pain: The SENZA-RCT randomized controlled trial. Anesthesiology 2015;123:851-60.

28. Kapural L, Yu C, Doust MW, et al. Comparison of 10-kHz high-frequency and traditional low-frequency spinal cord stimulation for the treatment of chronic back and leg pain: 24-month results from a multicenter, randomized, controlled pivotal trial. Neurosurgery 2016;79:667-77.

29. Russo M, Verrills P, Mitchell B, Salmon J, Barnard A, Santarelli D. High frequency spinal cord stimulation at 10 $\mathrm{kHz}$ for the treatment of chronic pain: 6-month Australian clinical experience. Pain Physician 2016;19:267-80.

30. Kramer J, Liem L, Russo M, Smet I, Van Buyten JP, Huygen F. Lack of body positional effects on paresthesias when stimulating the dorsal root ganglion (DRG) in the treatment of chronic pain. Neuromodulation 2015;18:50-7; discussion 57.

31. Liem L, Russo M, Huygen FJ, et al. One-year outcomes of spinal cord stimulation of the dorsal root ganglion in the treatment of chronic neuropathic pain. Neuromodulation 2015;18:41-8; discussion 48-9.

32. Deer TR, Levy RM, Kramer J, et al. Dorsal root ganglion stimulation yielded higher treatment success rate for complex regional pain syndrome and causalgia at 3 and 12 months: a randomized comparative trial. Pain 2017;158:669-81.

33. Eldabe S, Buchser E, Duarte RV. Complications of spinal cord stimulation and peripheral nerve stimulation techniques: a review of the literature. Pain Med 2016;17:325-36.

34. Bendersky D, Yampolsky C. Is spinal cord stimulation safe? A review of its complications. World Neurosurg 2014;82:1359-68.

35. Turner JA, Loeser JD, Deyo RA, Sanders SB. Spinal cord stimulation for patients with failed back surgery syndrome or complex regional pain syndrome: a systematic review of effectiveness and complications. Pain 2004;108:137-47.

36. Cameron T. Safety and efficacy of spinal cord stimulation for the treatment of chronic pain: a 20-year literature review. J Neurosurg 2004;100(3 Suppl Spine):254-67.

37. Follett KA, Boortz-Marx RL, Drake JM, et al. Prevention and management of intrathecal drug delivery and spinal cord stimulation system infections. Anesthesiology 2004;100:1582-94

38. Rudiger J, Thomson S. Infection rate of spinal cord stimulators after a screening trial period. A 53-month third party follow-up. Neuromodulation 2011;14:136-41; discussion 141. 